\title{
Corrosion Inhibition of Amino Pentadecylphenols (APPs) Derived from Cashew Nut Shell Liquid on Mild Steel in Acidic Medium
}

\author{
Joseph Yoeza Naimani Philip1 ${ }^{*}$, Joseph Buchweshaija ${ }^{1}$, Alinanuswe Mwakalesi',2 \\ ${ }^{1}$ Chemistry Department, University of Dar es Salaam, Dar es Salaam, Tanzania \\ ${ }^{2}$ Physical Sciences Department, Sokoine University of Agriculture, Morogoro, Tanzania \\ Email: "jynphilip@udsm.ac.tz
}

Received 8 May 2016; accepted 2 August 2016; published 5 August 2016

Copyright (C) 2016 by authors and Scientific Research Publishing Inc.

This work is licensed under the Creative Commons Attribution International License (CC BY). http://creativecommons.org/licenses/by/4.0/

(c) (i) Open Access

\begin{abstract}
In this study, corrosion inhibiting properties of amino pentadecylphenols (APPs) derived from Cashew Nut Shell Liquid (CNSL) on mild steel in aerated $0.10 \mathrm{M} \mathrm{HCl}$ at $303 \mathrm{~K}$ were studied using Electrochemical Impedance Spectroscopy (EIS) and potentiodynamic polarization measurements. Both methods indicated the potential of a mixture of amino pentadecyphenols to serve as a corrosion inhibitor in mild steel in $0.10 \mathrm{M} \mathrm{HCl}$. Corrosion inhibition efficiencies were observed to increase with increase in the inhibitor concentration, with maximum corrosion inhibition of about $98 \%$ at inhibitor concentration of $600 \mathrm{ppm}$. The adsorption of the inhibitor on mild steel surface was found to obey Temkin adsorption isotherm, signifying physical adsorption of the inhibitor molecules on mild steel surface.
\end{abstract}

\section{Keywords}

Corrosion Inhibitor, Cashew Nut Shell Liquid, Amino Pentadecylphenols, Mild Steel

\section{Introduction}

Mild steel substances are the most widely used group of materials in construction and industrial applications. However, the usefulness of these materials is challenged by corrosion, an electrochemical reaction that results into gradual destruction of metallic substrates through anodic dissolution [1]. Due to the economic damage and mild

${ }^{*}$ Corresponding author.

How to cite this paper: Philip, J.Y.N., Buchweshaija, J. and Mwakalesi, A. (2016) Corrosion Inhibition of Amino Pentadecylphenols (APPs) Derived from Cashew Nut Shell Liquid on Mild Steel in Acidic Medium. Materials Sciences and Applications, 7, 396-402. http://dx.doi.org/10.4236/msa.2016.78036 
steel corrosion can cause, it persists as a serious subject of research especially with a view to minimize its effects.

In general, metal corrosion mitigation techniques include proper design, the use of corrosion resistant alloys, metal surface modification (e.g., coating, galvanizing and electroplating), electrical control (e.g., anodic protection), electrochemical technique (e.g., cathodic protection) and modification of the environment directly in contact with the metallic structure (e.g., $\mathrm{pH}$ adjustment, removal of corrosive species and the use of corrosion inhibitors).

The use of corrosion inhibitors to modify the environment in which a metallic substrate is used, especially in piping and storage systems, is considered to be the most versatile, practical and economical [2]. A corrosion inhibitor is a chemical substance that is added in small concentration to the corrosive media. Although the concentration of the inhibitor should be small which does not alter physical characteristics of the media, it should be sufficient to reduce significantly the rate of metal corrosion [3].

As reported elsewhere [4], acidic solutions are used in pickling, cleaning, descaling and etching of mild steel. In these solutions, the dissolution rate of mild steel is quite high and application of corrosion inhibitors to reduce corrosion rate is of paramount significance. The majority of organic corrosion inhibitors are those containing heteroatoms such as oxygen, sulfur or nitrogen. Among these are amines containing organic compounds, which are reported to be effective corrosion inhibitors in aqueous acidic environments [5].

In an effort to synthesize poly(APP-co-EGDMA) [6], we recently reported modification of Cashw Nut Shell Liquid (CNSL) to form a mixture of amino pentadecylphenols (APPs), i.e. 5-pentadecyl-2,4-diaminophenol and 3-pentadecyl-2,4,6-triaminophenol. The surfactant chemical structures of these APPs stimulated our interest to investigate their corrosion inhibiting properties on mild steel in aqueous acidic media, including investigation of the inhibitor adsorption isotherms which are herein reported.

\section{Materials and Methods}

\subsection{Corrosion Inhibitor}

The corrosion inhibitor used in this study is a mixture of APPs, i.e. 5-pentadecyl-2,4-diaminophenol and 3-pentadecyl-2,4,6-triaminophenol synthesized as reported somewhere else [6].

\subsection{Corrosion Studies}

Two electrochemical techniques were used for the mild steel corrosion measurements, i.e., Electrochemical Impedance Spectroscopy (EIS) and potentiodynamic polarization. The measurements were conducted in an electrochemical cell containing $0.10 \mathrm{M} \mathrm{HCl}$ electrolyte, mild steel working electrode, $\mathrm{Ag} / \mathrm{AgCl}$ reference electrode and stainless steel counter electrode. The working electrode used in this study was made from mild steel acquired from Dar es Salaam Water and Sewage Company (DAWASCO), Dar es Salaam, Tanzania.

\subsection{Working Electrode}

All measurements were performed using mild steel disk electrode made from parent metal of the composition presented in Table 1. The disk specimens were polished using silicon carbide papers of increasing grits, i.e. 800, 2400 and finally 4000 grit, followed by polishing with diamond paste ( $9 \mu \mathrm{m}$ to $1.0 \mu \mathrm{m}$ ) to achieve mirror surface finish. After rinsing with distilled water, the specimens were degreased by sonication in ethanol (about 15 minutes) and subsequently followed in acetone (about 3 minutes). The mild steel electrodes were embedded in epoxy resin, to expose a surface area of $0.85 \mathrm{~cm}^{2}$ to $0.10 \mathrm{M} \mathrm{HCl}$ electrolyte. The tests were carried out in a 100 $\mathrm{mL}$ three electrodes thermostatically controlled cell made of Pyrex glass. The clean working electrode was immediately introduced into the electrolyte.

\subsection{Electrochemical Measurements}

The potentiodynamic measurements were performed using a computer controlled PGSTAT20 potentiostat from

Table 1. The chemical composition of mild steel electrod in weight percentage.

\begin{tabular}{|c|c|c|c|c|c|c|c|c|}
\hline Element & $\mathrm{C}$ & $\mathrm{Si}$ & $\mathrm{Mn}$ & $\mathrm{Al}$ & $\mathrm{Cr}$ & $\mathrm{Ni}$ & V & $\mathrm{Fe}$ \\
\hline Wt (\%) & 0.172 & 0.020 & 0.443 & $<0.0005$ & 0.210 & 0.071 & $<0.0005$ & $<98.31$ \\
\hline
\end{tabular}


ECO CHEMIE, Netherlands. Polarization measurements were recorded on the specimens by sweeping the potential from the open circuit potential to both cathodic and anodic directions. Cathodic sweep was done first, and then the system was allowed to return to its original open circuit potential before recording the anodic sweep. The sweeping rate was $1 \mathrm{mV} / \mathrm{s}$ over a range of $100 \mathrm{mV}$ vs. $\mathrm{Ag} / \mathrm{AgCl}$ from the open circuit potential.

A computer aided Autolab PGSTAT20 Frequency Response Analyser (FRA) was used in the electrochemical impedance measurement in the frequency range of $10 \mathrm{kHz}$ to $10 \mathrm{mHz}$ at a sweeping rate of 10 points per decade, logarithmic division. The resulting data were analyzed by fitting them to Equivalent Circuits (EC). The EC parameters for the charge transfer resistance, $R_{\mathrm{ct}}$, and electrochemical double layer capacitance, $C_{\mathrm{d} 1}$, were obtained using a complex non-linear least square fitting programme, EQUIVCRT, developed by Boukamp. The potential of zero charge was determined from the $C_{\mathrm{d} 1}$ values obtained at various open circuit potentials. The determined potential of zero charge was compared with the stable value of open circuit potential so as to determine the charge on the metal surface. The $R_{\mathrm{ct}}$ values were used to calculate the corrosion current density using Stern Geary relation.

\section{Results and Discussion}

\subsection{Polarization Measurements}

Some of the polarization curves for mild steel electrode in aerated $0.10 \mathrm{M} \mathrm{HCl}$ in absence and presence different concentrations of the inhibitor at $303 \mathrm{~K}$ are presented in Figure 1. As seen in Figure 1, both anodic and cathodic current densities decrease with increasing concentration of the inhibitor. This indicates adsorption of the inhibitor molecules on the mild steel surface, a result which is in agreement with findings reported elsewhere [7]. Since APPs inhibitor affects both the anodic and cathodic polarisation curves, it may be said to exhibit a mixed type of inhibitor. However, the anodic shift of the open circuit potential with increasing inhibitor concentration shows that the inhibitor has a predominant anodic effect [8]. In addition, the polarization curves taken at the inhibitor concentration of $600 \mathrm{ppm}$ and $800 \mathrm{ppm}$ were almost superimposed, indicating an optimum inhibitor concentration of $600 \mathrm{ppm}$.

Electrochemical parameters presented in Table 2 were obtained from these curves by Tafel lines extrapolation [9] as function of the inhibitor concentrations. These parameters are: corrosion potential, $E_{\text {corr }}$, corrosion current density, $i_{c o r r}$, anodic and cathodic Tafel slopes $b_{a}$ and $b_{c}$ respectively, corrosion rate, $V_{\text {corr }}$, and inhibitor efficiencies, $\theta$.

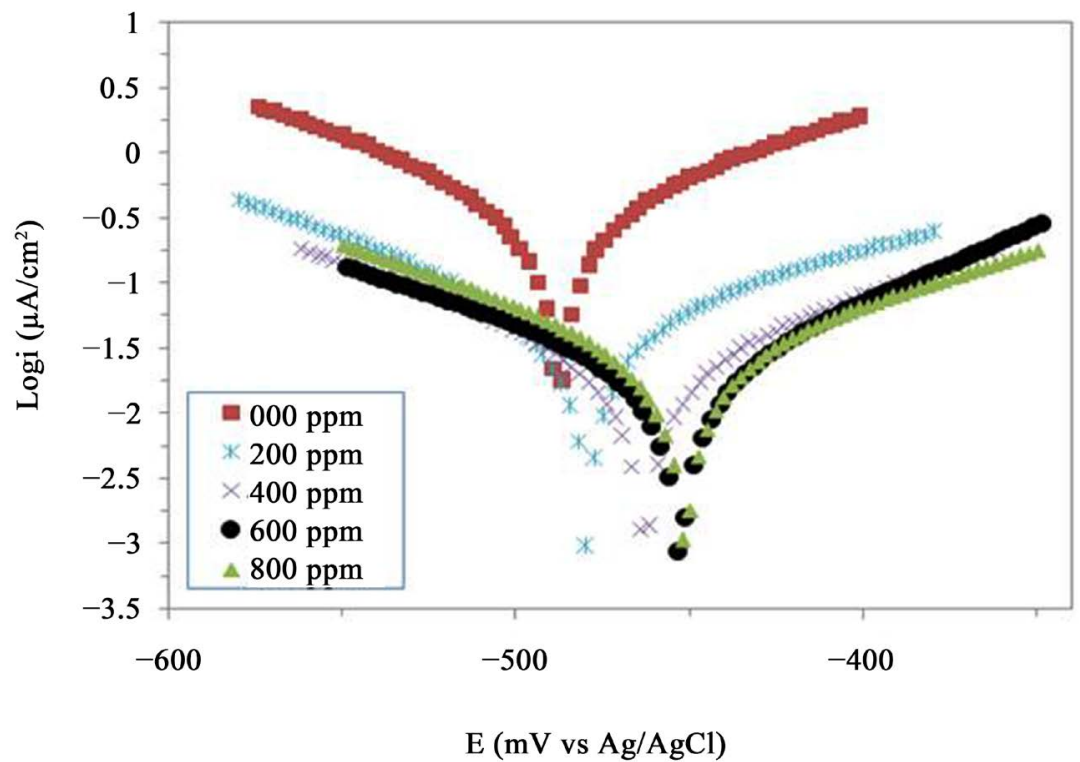

Figure 1. Polarization curves for mild steel working electrodes recorded after 3 hrs of exposure in $0.10 \mathrm{M} \mathrm{HCl}$ at $303 \mathrm{~K}$ in the absence and presence of different concentrations of APPs inhibitor. 
Table 2. Electrochemical parameters obtained from polarization measurements, calculated corrosion rates and inhibitor efficiencies for mild steel electrodes exposed for 3 hrs at $303 \mathrm{~K}$ in $0.10 \mathrm{M} \mathrm{HCl}$ solutions in the absence and presence of different concentrations of APPs.

\begin{tabular}{|c|c|c|c|c|c|c|}
\hline $\begin{array}{c}C_{\text {inh }} \\
(\mathrm{ppm})\end{array}$ & $\begin{array}{c}b_{a} \\
\text { (mV/decade) }\end{array}$ & $\begin{array}{c}b_{c} \\
\text { (mV decade) }\end{array}$ & $\begin{array}{c}E_{\text {corr }} \\
(\mathrm{mV} \text { vs Ag/AgCl) }\end{array}$ & $\begin{array}{c}i_{\text {corr }} \\
\left(\mu \mathrm{A} \cdot \mathrm{cm}^{-2}\right)\end{array}$ & $\begin{array}{c}V_{\text {corr }} \\
\left(\mathrm{mm} \cdot \mathrm{y}^{-1}\right)\end{array}$ & $\begin{array}{c}\theta \\
(\%)\end{array}$ \\
\hline Blank & 38 & -35 & -488 & 89.44 & 1.037 & - \\
\hline 25 & 35 & -17 & -486 & 71.53 & 0.829 & 20.02 \\
\hline 50 & 28 & -17 & -485 & 54.00 & 0.625 & 39.62 \\
\hline 100 & 16 & -13 & -484 & 35.12 & 0.407 & 60.73 \\
\hline 200 & 14 & -13 & -479 & 19.62 & 0.227 & 78.06 \\
\hline 400 & 16 & -17 & -463 & 6.85 & 0.079 & 92.34 \\
\hline 600 & 20 & -14 & -453 & 2.61 & 0.030 & 97.08 \\
\hline 800 & 14 & -12 & -452 & 2.57 & 0.029 & 97.12 \\
\hline
\end{tabular}

The values for $E_{\text {corr }}$ and $i_{\text {corr }}$ were obtained via the intersection of the anodic and cathodic Tafel lines. The anodic and cathodic Tafel slopes are given by $b_{a}=2.303(R T / \beta n F)$ and $b_{c}=-2.303(R T / \beta n F)$, respectively, where $R$ is the gas constant, $T$ is absolute temperature, $F$ is Faraday's constant, $n$ is number of participating electrons and $\beta$ is symmetry coefficient for the anodic or cathodic reaction associated with charge transfer resistance. Corrosion rates were calculated by assuming a uniform corrosion using Equation (1) as:

$$
V_{\text {corr }}=\frac{315 W i_{\text {corr }}}{n F \rho}
$$

where $W$ is atomic mass of the metal $\left(\mathrm{g} \cdot \mathrm{mol}^{-1}\right)$, in this case iron; $i_{\text {corr }}$ is corrosion current $\left(\mu \mathrm{A} \cdot \mathrm{cm}^{-2}\right)$; and $\rho$ is density of the metal $\left(\mathrm{g} \cdot \mathrm{cm}^{-3}\right)$ [10]. The corrosion inhibition efficiency, $\theta$ (\%) was calculated using Equation (2) as:

$$
\phi=100\left(1-\frac{V_{c o r r, i}}{V_{c o r r, u}}\right)
$$

where $V_{\text {corr, } i}$ and $V_{\text {corr, } u}$ are the corrosion rates with and without inhibitor, respectively.

From Table 2, it can be observed that the $b_{a}$ and $b_{c}$ did not vary significantly with the increase in inhibitor concentration. This can be suspected that the inhibitor possibly acted by blocking the available anodic and cathodic sites on the mild steel surface. In other words, the inhibitor decreased the surface area for corrosion process and inactivated parts of the mild steel surface with respect to corrosive medium. It was further observed that the $E_{\text {corr }}$ shifted anodically with increasing concentration of APPs inhibitor. As mentioned elsewhere [8], such observation indicates that the addition of the inhibitor principally affect the anodic process, hence APPs inhibitor acts predominantly as anodic type. The corrosion current densities (Table 2) changed from $89.44 \mu \mathrm{A} \cdot \mathrm{cm}^{-2}$ for blank solution to $2.230 \mu \mathrm{A} \cdot \mathrm{cm}^{-2}$ in the presence of $600 \mathrm{ppm}$ of APPs inhibitor. Further increase in APPs inhibitor concentration in the electrolyte did not show a significant additional reduction of current density, indicating the minimum concentration of APPs giving optimum corrosion protection. In addition, as seen in Table 2, APPs inhibitor concentration of $600 \mathrm{ppm}$ resulted in reduction of corrosion rate from $1.037 \mathrm{~mm} \cdot \mathrm{y}^{-1}$ to $0.030 \mathrm{~mm} \cdot \mathrm{y}^{-1}$, corresponding to over $97 \%$ corrosion inhibition efficiency.

\subsection{Electrochemical Impedance Spectroscopy Measurements}

The impedance plots for mild steel electrode in aerated $0.10 \mathrm{M} \mathrm{HCl}$ in absence and presence different concentrations of the inhibitor at $303 \mathrm{~K}$ are presented in Figure 2.

As can be observed from Figure 2, the plots are characterized by a single capacitive loop and depressed semicircles whose sizes increase with the increase in inhibitor concentration. The depressed semicircles in impedance measurements ploted in Nyquist format are referred to as frequency depressions and have been 


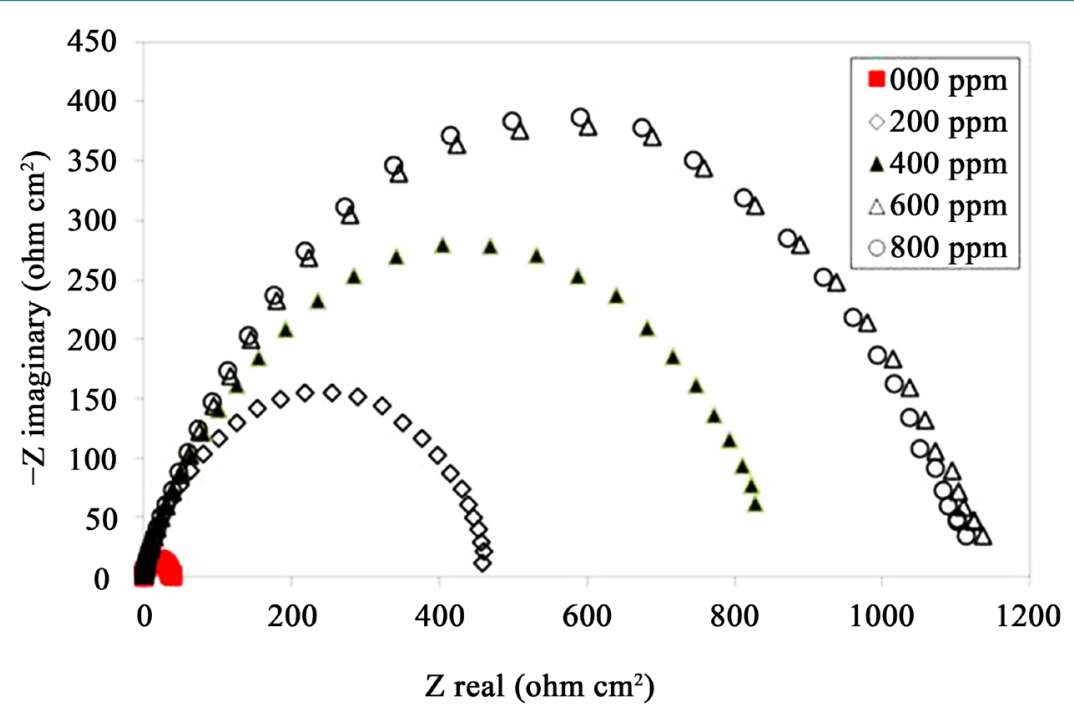

Figure 2. Impedance plots in Nyquist format for mild steel working electrodes recorded after $3 \mathrm{hrs}$ of exposure in $0.10 \mathrm{M} \mathrm{HCl}$ at $303 \mathrm{~K}$ in the absence and presence of different concentrations of APPs inhibitor.

reported to be attributed to surface in homogeneities. The increase in size of the semicircles with increase in inhibitor concentration is reported to be due to charge transfer resistance at the metal/solution interface [11] [12]. This signifies that an increase in the APPs concentration resulted into reduction in Faradic processes taking place at the surface covered by the inhibitor resulting into decreased corrosion rate. Furthermore, the largest size of the semicircles was obtained with inhibitor concentration of $600 \mathrm{ppm}$. A further increase in concentration of the APPs inhibitor above $600 \mathrm{ppm}$ did not change the size and shape of the semicircles. Thus, as for polarization measurements, $600 \mathrm{ppm}$ can be regarded as the optimum concentration of APPs for the tested mild steel in $0.10 \mathrm{M} \mathrm{HCl}$ solution. Electrochemical parameters obtained from impedance measurements on mild steel electrodes in $0.10 \mathrm{M} \mathrm{HCl}$ solutions in the absence and presence of different concentrations of APPs inhibitor recorded after $3 \mathrm{hrs}$ of exposure at $303 \mathrm{~K}$ are summarised in Table 3 . These parameters are: open circuit potential, $E_{o c p}$, charge transfer resistance, $R_{c t}$, and double layer capacitance, $C_{d l}$; obtained as stated in Section 2.3.

It is clearly observed from Table 3 that as the APPs inhibitor concentration was increased, the $R_{c t}$ values increased and the $C_{d l}$ values decreased. These results can be attributed to the decrease in the thickness of double layer due to the replacement of the electrolyte molecules on mild steel surface by adsorption of the APPs inhibitor molecules [13]. Similar findings were also reported elsewhere [14]-[16].

\subsection{Adsorption Isotherms}

In order to understand mechanism through which the APPs inhibitor molecules adsorbed on the mild steel electrode exposed in $0.10 \mathrm{M} \mathrm{HCl}$ electrolyte, it was important to use Temkin adsorption isotherm model. The predominant adsorption isotherm models depend on several factors including temperature, type of anions and chemical changes of the inhibitor. The relevant equation for Temkins adsorption isotherm model is Equation (3).

$$
e^{-2 a \theta}=K C_{i n h}
$$

where $\theta$ is the degree of surface coverage, $C_{i n h}$ is the APPs inhibitor concentration in the electrolyte, $K$ is the adsorption equilibrium constant and $a$ is the attractive parameter. Making $\theta$ the subject and applying logarithm gives Equation (4).

$$
\theta=\frac{-2.303 \log K}{2 a}-\frac{2.303 \log C_{i n h}}{2 a} .
$$


Table 3. Electrochemical parameters obtained from polarization measurements, calculated corrosion rates and inhibitor efficiencies for mild steel electrodes exposed for $3 \mathrm{hrs}$ at $303 \mathrm{~K}$ in $0.10 \mathrm{M} \mathrm{HCl}$ solutions in the absence and presence of different concentrations of APPs.

\begin{tabular}{ccccccc}
\hline $\begin{array}{c}C_{\text {inh }} \\
(\mathrm{ppm})\end{array}$ & $\begin{array}{c}E_{\text {ocp }} \\
(\mathrm{mV} \text { vs Ag/AgCl })\end{array}$ & $\begin{array}{c}R_{\mathrm{ct}} \\
\left(\Omega \cdot \mathrm{cm}^{2}\right)\end{array}$ & $\begin{array}{c}C_{\mathrm{dl}} \\
\left(\mu \mathrm{F} \cdot \mathrm{cm}^{2}\right)\end{array}$ & $\begin{array}{c}i_{\text {corr }} \\
\left(\mu \mathrm{A} \cdot \mathrm{cm}^{-2}\right)\end{array}$ & $\begin{array}{c}V_{\text {corr }} \\
\left(\mathrm{mm}_{\mathrm{y}} \mathrm{y}^{-1}\right)\end{array}$ & $\begin{array}{c}\theta \\
(\%)\end{array}$ \\
\hline Blank & -492 & 36 & 219 & 229.73 & 2.6625 & - \\
25 & -488 & 44 & 102 & 118.05 & 1.3681 & 19.07 \\
50 & -487 & 60 & 88 & 80.03 & 0.9275 & 40.21 \\
100 & -485 & 89 & 57 & 36.58 & 0.4240 & 59.87 \\
200 & -478 & 156 & 50 & 19.61 & 0.2273 & 77.02 \\
400 & -462 & 524 & 35 & 7.14 & 0.0828 & 93.14 \\
600 & -456 & 2400 & 31 & 1.56 & 0.0181 & 98.50 \\
800 & -456 & 2432 & 31 & 1.21 & 0.0140 & 98.52 \\
\hline
\end{tabular}

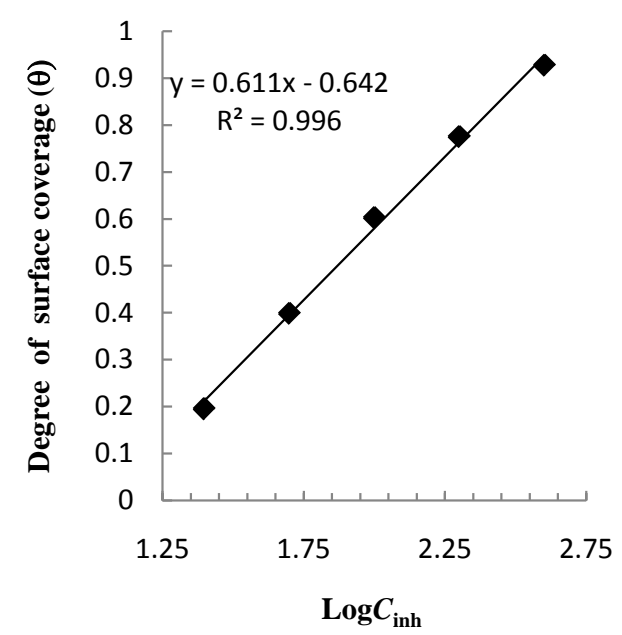

Figure 3. Temkin isotherm for adsorption of APPs inhibitor on mild steel working electrodes exposed in $0.10 \mathrm{M} \mathrm{HCl}$ at $303 \mathrm{~K}$.

Equation (4) suggests a plot of $\theta$ against $\log C_{\text {inh }}$ to give a straight line with slope equal to $-2.303 / 2 a$ and intercept equal to $-2.303 \log K / 2 a$. The degrees of surface coverage at different APPs inhibitor concentrations were calculated from corrosion inhibition efficiencies, i.e., $\theta=\phi / 100=1-\left(V_{\text {corr }, i} / V_{\text {corr }, u}\right)$ using data in Table 2 and Table 3. Since the APPs inhibitor efficiencies obtained from the two electrochemical techniques were very close to each other, the average values were used. A plot of $\theta$ against $\log C_{\text {inh }}$ is presented in Figure 3.

As expected, the results from this study were found to obey Temkin adsorption isotherm (Figure 3) with $R^{2}=0.996$. From the slope of the regression line (0.611), $a=-1.885$ indicating an existence of repulsion in the adsorption layer. From the intercept of the regression line (0.642), $K=0.089$. Since the equilibrium constant obtained in this work is relatively small, it can be suspected that interaction between the APPs inhibitor molecules and the mild steel surface was by physical adsorption [17].

\section{Conclusion}

A mixture of amino pentadecylphenols derived from the chemical modification of cashew nut shell liquid was used as corrosion inhibitor for carbon steel in $0.1 \mathrm{HCl}$ at $303 \mathrm{~K}$. The results from potentiodynamic measurements signified that APPs inhibitor is a mixed type of inhibitor with a predominant anodic effect. Both electrochemical methods reveal an optimum concentration of APPs inhibitor in $0.10 \mathrm{M} \mathrm{HCl}$ solution to 
be 600 ppm. From Temkins adsorption isotherm model, the adsorption of APPs inhibitor molecules was found to be physisorption. Therefore, APPs corrosion inhibitor is a potential corrosion inhibitor in acidic media.

\section{References}

[1] Revie, R.W. and Revie, H.H. (2008) Corrosion and Corrosion Control. 4th Edition, John Wiley \& Sons, Inc., Hoboken, NJ.

[2] Arshadi, M.R., Lashgari, M. and Parsafar, Gh. A. (2004) Cluster Approach to Corrosion Inhibition Problems: Interaction Studies. Materials Chemistry and Physics, 86, 311-314. http://dx.doi.org/10.1016/j.matchemphys.2004.03.028

[3] Ibrahim, T.M. and Zour, M.A. (2011) Corrosion Inhibition of Mild Steel Using Fig Leaves Extract in Hydrochloric Acid Solution. International Journal of Electrochemical Science, 6, 6442-6455.

[4] Anejjar, A., Salghi, R., Zarrouk, A., Benali, O., Zarrok, H., Hammouti, B., Al-Deyab, S.S., Benchat, N. and Elaatiaoui, A. (2013) Adsorption and Corrosion Inhibition of Steel in Hydrochloric Acid Solution by 3-Bromo-2-phenylimidazol [1,2- $\alpha$ Pyridine. International Journal of Electrochemical Science, 8, 11512-11525.

[5] Rani, B.E.A. and Basu B.B.J. (2012) Green Inhibitors for Corrosion Protection of Metals and Alloys: An Overview. International Journal of Corrosion, 2012, Article ID: 380217.

[6] Wilson, J., Philip, J.Y.N. and Mdoe, J.E.G. (2014) Synthesis of Poly(APP-co-EGDMA) Particles Using Monomers Derived from Cashew Nut Shell Liquid for the Removal of Cr(III) from Aqueous Solutions. Open Journal of Organic Polymer Materials, 4, 29-36. http://dx.doi.org/10.4236/ojopm.2014.41005

[7] Singh, A., Ebenso, E.E. and Quraishi, M.A. (2012) Corrosion Inhibition of Carbon Steel in HCl Solution by Some Plant Extracts. International Journal of Corrosion, 2012, Article ID: 897430. http://dx.doi.org/10.1155/2012/897430

[8] Finšgar, M. and Jackson, J. (2014) Application of Corrosion Inhibitors for Steels in Acidic Media for the Oil and Gas Industry: A Review. Corrosion Science, 86, 17-41. http://dx.doi.org/10.1016/j.corsci.2014.04.044

[9] Roberge, P.R. (2000) Handbook of Corrosion Engineering. McGraw-Hill, New York.

[10] ASTM (1999) Standard Practice for Calculation of Corrosion Rates and Related Information from Electrochemical Measurements, Designation: G 102-89. American Society for Testing and Materials, West Conshohocken.

[11] Buchweishaija, J. (1997) Inhibiting Properties and Adsorption of an Amine Based Fatty Acid Corrosion Inhibitor on Carbon Steel in Aqueous Carbon dioxide Solution. Ph.D. Thesis, Norwegian University of Science and Technology, Trondheim.

[12] Khaled, K.F., Abdel-Shafi, N.S., Al-Mubarak, N.A. and Alonazi M.S. (2016) L-Arginine as Corrosion and Scale Inhibitor of Steel in Synthetic Reservoir Water. International Journal of Electrochemical Science, 11, 2433-2446.

[13] Wang, H.B., Shi, H., Hong, T., Kang C. and Jepson, W.P. (2001) Characterization of Inhibitor and Corrosion Product Film Using Electrochemical Impedance Spectroscopy (EIS). Corrosion 2001, Houston, TX, 11-16 March 2001, Paper No. 01023.

[14] Buchweishaija, J. (2009) Plants as a Source of Green Corrosion Inhibitors: The Case of Gum Exudates from Acacia Species (A. drepanolobium and A. senegal). Tanzania Journal of Science, 35, 93-106.

[15] Buchweishaija, J. and Mhinzi, G.S. (2008) Natural Products as a Source of Environmentally Friendly Corrosion Inhibitors: The Case of Gum Exudate from Acacia seyal var. seyal. Portugaliae Electrochimica Acta, 26, 257-265. http://dx.doi.org/10.4152/pea.2008032257

[16] Philip, J.Y.N., Buchweishaija, J. and Mkayula, L.L. (2001) Cashew Nut Shell Liquid as an Alternative Corrosion Inhibitor for Carbon Steels. Tanzania Journal of Science, 27, 9-19. http://dx.doi.org/10.4314/tjs.v27i1.18332

[17] Anaee, R.A., Alzuhairi, M.H. and Abdullah, H.A. (2014) Corrosion Inhibition of Steel in Petroleum Medium by Ficus carica Leaves Extract. Asian Journal of Engineering and Technology, 2, 235-243. 


\section{Submit or recommend next manuscript to SCIRP and we will provide best service for you:}

Accepting pre-submission inquiries through Email, Facebook, LinkedIn, Twitter, etc.

A wide selection of journals (inclusive of 9 subjects, more than 200 journals)

Providing 24-hour high-quality service

User-friendly online submission system

Fair and swift peer-review system

Efficient typesetting and proofreading procedure

Display of the result of downloads and visits, as well as the number of cited articles

Maximum dissemination of your research work

Submit your manuscript at: http://papersubmission.scirp.org/ 